\title{
ASSISTÊNCIA AOS PAIS DE RECÉM-NASCIDOS PRÉ-TERMO EM UNIDADES NEONATAIS
}

\author{
ASSISTANCE TO PARENTS OF PRETERM NEWBORNS IN \\ NEONATAL UNITS \\ ASISTENCIAALOS PADRES DE RECIÉN NACIDOS PRE-TÉRMINO EN \\ UNIDADES NEONATALES
}

\author{
Camen Gracinda Silvan Scochi' \\ Débora Falleiros de Mello ${ }^{1}$ \\ Luciana de Lione Melo ${ }^{2}$ \\ Maria Aparecida Munhoz Gaíva ${ }^{3}$
}

\begin{abstract}
RESUMO: O objetivo deste trabalho é refletir sobre a assistência aos pais de neonatos prematuros e de baixo peso ao nascer, em unidades neonatais, fundamentando-se em dados da literatura e em experiências práticas das autoras. Embora o direito materno de permanecer junto ao filho esteja assegurado por lei, a grande maioria dos berçários ainda mantém os horários restritos de visita. Todavia, já se dispōe de serviços que liberam totalmente a permanência materna nestes berçários, questionando se é permitido o envolvimento efetivo dos pais com os cuidados do filho. $\mathrm{Na}$ assistência de enfermagem, as autoras sugerem estratégias de intervenção visando a adaptação dos pais a nova situaçăo e o fortalecimento do vinculo entre pais e bebê, dentre elas destacam-se: o livre acesso dos pais ao berçário; incentivo ao contato físico precoce entre pais e filho; implantação de grupos de apoio envolvendo equipe multiprofissional e pais de bebês em diferentes estágios de evolução clínica; incentivo ao aleitamento materno e à execuçäo de cuidados diretos ao filho; implantação de redes de apoio formal e informal dirigidas aos pais durante a hospitalização do filho e após a alta hospitalar.
\end{abstract}

PALAVRAS-CHAVE: assistência de enfermagem, pais, recém-nascidos prematuros

\section{INTRODUÇÄO}

Nas últimas décadas o avanço da tecnologia médica tem sido marcante nos serviços de atenção neonatal, contribuindo para a diminuição da morbimortalidade em recém-nascidos. A assistência neonatal vem enfatizando os cuidados à saúde de crianças prematuras e de baixo peso ao nascer e cada vez mais a sobrevida dessas crianças tem sido uma conquista.

A prematuridade e o baixo peso ao nascer têm sido estudados sob vários enfoques e, em termos mundiais, é cada vez mais crescente a preocupação com os fatores de risco perinatais. Esta problemática agrava-se nos paises subdesenvolvidos ou em desenvolvimento devido às condições desfavoráveis de vida e à escassez de serviços especializados, comprometendo a qualidade da assistência.

Os recém-nascidos prematuros e de baixo peso constituem grupo de risco em relação a maior ocorrência de morbidade. O nascimento antes de 37 semanas de gestação traz riscos à

\footnotetext{
'Docente do Departamento de Enfermagem Materno-Infantil e Saúde Pública a EERP-USP, Área Enfermagem Pediátrica e Neonatal.

${ }^{2}$ Mestranda em Psicologia da Fac. de Filosofia, Ciências e Letras de Ribeiräo Preto - USP.

${ }^{3}$ Docente da UFMT. Doutoranda do Programa de Pós-Graduaçăo, Área Enfermagem em Saúde Pública, da EERP - USP.
} 
vida extra-uterina devido à imaturidade dos órgãos e ao elevado risco de morbimortalidade neonatal, pós-natal e durante a infância.

Assim como a prematuridade, o baixo peso ao nascer também aparece como causa importante de mortalidade perinatal. Essas crianças têm menores probabilidades de sobreviver e menores condições de desenvolvimento adequado se comparadas às crianças que nascem de peso normal.

Na literatura há estudos realizados em diferentes localidades, sendo apontado, de modo geral, os seguintes fatores predisponentes da prematuridade: primiparidade, baixo nivel sócioeconômico, idade matema (mães abaixo de 18 anos e acima de 35 anos), adolescentes solteiras, má nutrição materna e pequeno intervalo entre as gestações (Alberman; Evans, Avery et al, 1994). Muitas causas do nascimento prematuro e do baixo peso ao nascer são desconhecidas. Fatores biológicos foram evidenciados, mas tem sido atribuída crescente importância para a associação entre a incidência desses problemas e a situação sócio-econômica. Para Viggiano e Ximenes (1984) muito raramente o nascimento prematuro é determinado por algum fator específico, mas sim por uma associação de fatores dos quais as condições de vida estão estreitamente relacionadas.

Grande parte das familias de crianças prematuras e de baixo peso ao nascer é composta por mães e filhos, sem cônjuge, apresentando problemas sociais e de saúde associados à pobreza, como: uso de drogas e álcool, desnutrição materna, violência doméstica, doenças sexualmente transmissiveis e carências em relação aos cuidados à saúde (Zahr et al., 1989; Alberman; Evans, 1992, Gennaro, 1996).

Essas crianças, em geral, estão em situação de duplo risco, risco social e biológico, ou seja, há relações entre a vulnerabilidade a danos, riscos de adoecer e suas condiçőes de vida. A complexidade de todos estes problemas caracteriza a criança pré-termo e de baixo peso ao nascer como de risco, podendo ocorrer prejuizos em seu processo de crescimento e desenvolvimento.

Dentro das necessidades de cuidados à saúde de recém-nascidos prematuros e de baixo peso, alguns estudos vêm destacando como prioridade a participação da família e a assistência aos pais na atenção à saúde desta clientela. Em decorrência do longo período de internação, há problemas relativos à privação materna e separação prolongada do ambiente familiar, podendo causar aumento do estresse na família e prejuizo no estabelecimento do vínculo entre a mãe / familia e a criança. Entendemos que a criança não existe só, necessitando da familia para satisfazer suas necessidades e, portanto, as habilidades e dificuldades de quem desenvolve o cuidado dessas crianças, em geral a mãe, tornam-se integrantes na assistência à saúde. Assim, os pais desse grupo de crianças também têm sido considerados uma população de risco, por apresentarem vários sentimentos e dificuldades para cuidar dos filhos, necessitando de apoio durante a internação e após a alta hospitalar (McLoughlin, 1995).

Nos últimos anos, a participação dos pais, especialmente da mãe, na assistência à saúde da criança é uma temática que vem sendo explorada em vários estudos. Grande parte das investigações enfatizam a importância dos cuidados maternos e da permanência das mães junto aos filhos, durante a hospitalização das crianças, apresentando reflexões sobre a influência e os danos da separação mãe-filho nesse processo (Bowlby, 1995; Lamy, 1995, McLoughlin, 1995).

Com os avanços nos processos de diagnóstico e terapêutica na área de neonatologia, nas últimas décadas, e com o posterior acompanhamento da evolução e resultado a longo prazo das crianças prematuras, pesquisas envolvendo questões emocionais e comportamentais foram desenvolvidas em diversas áreas como a psicologia, a psicossomática e a fisiologia aplicada ao comportamento, permitindo que se tenha uma melhor compreensão do impacto do nascimento destas crianças no contexto familiar.

Assim, este trabalho consiste em uma reflexăo sobre a assistência aos pais de recém- 
nascidos prematuros e de baixo peso ao nascer em unidades de internação neonatal, fundamentando-se em dados da literatura e em experiências práticas das autoras em alguns serviços de saúde.

\section{TER UM FILHO PREMATURO}

A gestação e o nascimento são considerados um processo social, uma vez que afeta a relação entre o marido e a mulher e o contexto em que estão inseridos. Enquanto os pais aguardam a chegada do filho é comum idealizarem o mesmo passam meses sonhando e falando do filho, dando a ele caracteristicas físicas e até psicológicas que gostariam de ver realizadas e, mesmo quando essa criança nasce a termo, é natural ocorrer nos primeiros contatos um confronto entre o bebê ideal e o real. Essa reação dos pais é exacerbada por ocasião do nascimento de um bebê pré-termo.

O parto prematuro, tendo como resultado um bebê pequeno e frágil, altera o ritmo natural que envolve o nascimento de uma criança, podendo provocar alterações no funcionamento familiar e nos relacionamentos pessoais (Stjernvist 1992).

O bebê prematuro requer, muitas vezes, períodos de hospitalização prolongados numa unidade de internação neonatal, acontecimento esse que separa abruptamente a mãe do filho, podendo ocasionar estresse psicológico nos familiares, em especial na mãe.

As mães ao se depararem com seus filhos experimentam sentimentos de incompetência e frustração por não terem dado à luz ao filho sonhado. Os traços familiares que os pais buscam no filho recém-nascido, dificilmente são identificados no bebê tão pequeno e débil, que desperta-Ihes a lembrança de um bebê inacabado (Ferraz; Chaves, 1996).

A separação decorrente da internação do bebê gera nos pais tristeza, medo, estresse e culpa, pois os mesmos encontram-se fragilizados e inseguros quanto à vida de seus bebês. Este processo foi descrito por Klaus; Kenell (1982) como uma "reação de luto" que os pais sentem pela perda do bebê perfeito que não tiveram, necessitando de tempo e apoio para se adaptarem ao seu bebê real. Lamy(1995) enfatiza que o choque pela hospitalização de um bebê pode ser compreendido quando observamos os pais sendo confrontados, imprevisivelmente, com um ambiente estressante e confuso, impotentes para assumirem os cuidados de seu filho que apresenta possibilidades de morrer. Todos esses sentimentos podem ser atenuados ou reforçados de acordo com a oportunidade que essa mãe tem ou não de participar, de alguma forma, dos cuidados de seu filho.

A falta de oportunidade da mãe interagir efetivamente com seu filho hospitalizado poderá levar a um prejuizo do apego, ocasionando desordens no relacionamento futuro de ambos. As pesquisas evidenciam que o comportamento de apego se desenvolve desde a vida intra-uterina do bebê e que é fundamental o contato mãe e filho nos momentos iniciais da vida pós-natal (Brazelton,1988, Sluckin et al. 1990, Klaus; Kenell, 1993). Steele (1987) afirma que a privação da mãe em poder desenvolver as atividades de cuidados junto ao seu filho, poderá levá-la a sentir-se confusa sobre o que se espera dela neste periodo.

Os primeiros contatos entre mãe e filho constituem experiência dificil e angustiante para ambos, quando experimentam sentimentos de afeição, dúvida, medo, e só a partir de então começam a se conhecer um ao outro, a fazer trocas mútuas e desta maneira estabelecem gradativamente o apego entre mãe e filho (Berthould,1997).

Para a família de um bebê prematuro é muito difícil não só estabelecer como manter o vinculo com o filho. As dúvidas acerca de sua sobrevivência são muitas e o sentimento de culpa por ter tido um filho prematuro faz com que, muitas vezes, os pais se afastem dele até mostrar sinais concretos de que está fora de perigo.

A frustração de não poder pegar o bebê no colo, aconchegá-lo e embalá-lo é bastante forte. Muitas mães têm medo de tocar e acariciar o bebê dentro da incubadora ou de pegá-lo no 
colo, quando isso é possivel. Esse medo não vem somente da estranheza pelo ambiente hospitalar mas, possivelmente, porque a auto-estima da mãe está afetada; surge o medo de fazer mal ao bebê e a confiança na própria capacidade de criar o filho fica seriamente abalada (Badinter, 1985). Algumas mães demonstram sentimentos de inutilidade ao perceberem que somente os profissionais da equipe de saúde podem proteger seus bebês.

Alguns outros aspectos que envolvem o processo de internação de um bebê prematuro devem ser considerados, como é o caso da relação da equipe de saúde com os pais. Para os profissionais que atuam junto a esses bebês, essa relação nem sempre é fácil, a equipe sentese pressionada pela ansiedade deles e pela gravidade da condição clínica de alguns bebês, tem dificuldades em compreender certos pais que não visitam o filho, rotulando-os de "rejeitadores", e tendem a despersonalizar e infantilizá-los. Além do mais, muitas vezes, os profissionais sentem-se vigiados nos procedimentos que executam na unidade (Ferraz; Chaves, 1996).

É extremamente importante para os profissionais que atuam junto a estes bebês e seus pais, estarem conscientes da importância da afetividade e do estabelecimento do vinculo mãefilho e familia, tanto para diminuir os niveis de ansiedade e estresse dos pais quanto para que, no futuro, essa criança faça parte integrante do núcleo familiar (Waher; Kristiansen, 1995).

Os pais de bebês nascidos prematuros têm grandes possibilidades de desenvolverem uma relação desarmoniosa com seus filhos. Estudos apontam maior ocorrência de abusos, espancamentos, maus tratos e ainda a presença da sindrome failure to thrive ${ }^{4}$, entre essas crianças, devido aos efeitos da separação entre mãe-filho. A qualidade dos cuidados que a criança recebe dos pais é de suma importância para o seu desenvolvimento futuro, sendo que o estabelecimento do vinculo é influenciado pelo contato físico pele-a-pele, contato visual e amamentação (Klaus; Kennell, 1982). Contudo, os autores alertam que as ações e reações dos pais em relação ao filho são frutos de uma combinação de fatores, destacando a importância da vivência dos pais enquanto filhos de outrem, condições socioeconômicas, ajustamento familiar anterior ao parto, dentre outros.

\section{ASSISTÊNCIAAOS PAIS NOS SERVIÇOS DE NEONATOLOGIA}

A questão da humanização da assistência hospitalar há muito vem sendo discutida, e um dos pontos básicos é o contato e a interação o mais precoce possivel entre mãe e filho, bem como a incorporação dos pais no cuidado ao bebê internado. Contudo, são poucos os serviços que efetivamente desenvolvem intervenções dirigidas à mãe, pai e família.

A permanência da mãe ao lado da criança hospitalizada é um direito de cidadania, garantido pelo Estatuto da Criança e do Adolescente (BRASIL,1991), mas apesar da lei, essa não é uma prática comum em nossas instituições. Em muitos hospitais os pais estão ausentes e ainda são considerados intrusos na unidade de internação, e essa ausência é justificada pelos riscos de infecção a que os bebês prematuros estão sujeitos.

Entre as experiências relatadas na literatura que visam uma maior interação pais-filhos, o alojamento conjunto para mães de prematuros, prática desenvolvida em alguns países, mostra redução na morbimortalidade dessas crianças. Uma das estratégias relatadas é o "cuidado canguru", que é mencionado como uma medida eficaz, aumentando a lactação materna, a confiança da mãe nos cuidados ao filho e a relação de apego. Todavia, a simples implantação do "cuidado canguru" ou do alojamento conjunto tardio, sem que os profissionais tenham a dimensão exata do novo recorte intelectual que instrumentaliza essa prática, não assegura o alcance dos objetivos almejados. Javorski (1997), em estudo realizado na primeira instituição

${ }^{4}$ Failure to thrive é uma sindrome, na qual, sem uma causa organnica aparente, o recémnascido não ganha peso e não se desenvolve (Klaus; Kennel, 1982). 
brasileira a implantar o cuidado canguru, verificou que as intervenções da enfermagem priorizavam os aspectos técnicos do aleitamento materno, não contemplando as vivências, dificuldades e subjetividade das mães; algumas atitudes geravam conflitos, sentimentos de culpa e ansiedade nessas mães.

Em relação a nossa prática na assistência ao prematuro, observamos que é cada vez mais forte a tendência dos profissionais de saúde estarem atentos, o mais precocemente possivel, quanto ao estabelecimento do contato e interação entre mãe e filho, todavia, é raro o serviço que desenvolve intervenções dirigidas ao pai e à família, envolvendo inclusive os irmãos de neonatos prematuros.

Em visita realizada em um hospital de referência terciária na atenção perinatal, em Manchester-UK, tivemos oportunidade de observar na unidade de cuidados intermediários o envolvimento de toda a família com um bebê prematuro. A enfermeira acompanhava a visita dos familiares, estimulando que o irmão, de cerca de 3 anos de idade, interagisse com o bebê através do toque e da fala.

Ao discutirmos tal prática em nosso Grupo de Estudos em Enfermagem Neonatal, os enfermeiros de um hospital - escola de Ribeirão Preto - SP, sensibilizados com a problemática das famílias de bebês prematuros assistidos na unidade de cuidado intensivo neonatal (UCIN), implantaram programa com os avós e irmãos do prematuro, no qual é possibilitado o contato desses familiares com o bebê, sendo o agendamento dessas visitas programado em horários de menor fluxo de pessoal na UCIN e berçário de prematuros e de forma a possibilitar um acompanhamento da interação familia-bebê pela enfermeira.

Tal experiência, embora recente, tem sido extremamente positiva para a família, merecendo incentivar a sua expansão para outros serviços neonatais.

Ferraz e Chaves (1996) recomendam que, durante a internação, os pais tenham acesso a grupos de apoio e de discussão, ou a palestras proferidas por pessoas que já passaram por experiências semelhantes; quando possivel, os encontros devem ser intermediados por profissionais da área de saúde mental. Para Oheler (1993), a equipe da unidade neonatal deve apoiar os pais durante a hospitalização a fim de facilitar o vínculo entre eles e a criança, permitindo o contato físico pais-bebê.

Klaus e Kennell (1995) referem que, em anos recentes, os grupos de pais de prematuros têm sido formados em várias unidades neonatais para discussões de uma ou duas horas, realizadas semanalmente ou com maior freqüência. Os relatos documentados dessas experiências sugerem que os pais encontram, além do apoio, um considerável alivio por terem a oportunidade de conversar, expressar e comparar seus sentimentos íntimos.

Em relação à nossa prática na assistência ao prematuro, observamos algumas diferenças entre os serviços neonatais. No hospital-escola público de Ribeirão Preto-SP, citado anteriormente, o alojamento conjunto tardio não é uma realidade, mas sim um desejo de alguns profissionais. A visita dos pais ao bebê de alto risco é liberada, permitindo-se a permanência dos pais junto ao filho internado, bem como o contato pele-a-pele, sempre que possível. A enfermeira acompanha a mãe na primeira visita, procurando apoiá-la e fornecendo informações básicas sobre os equipamentos que cercam o recém-nascido; o pediatra informa a condição clínica do bebê. Os pais participam de um grupo de apoio, juntamente com outros pais que passaram pela experiência de terem seus recém-nascidos em estado grave. Nessas reuniões, coordenadas pela enfermeira e pediatra, eles recebem informações sobre a condição clínica e terapêutica do filho, esclarecem suas dúvidas e trocam experiências com os outros pais. Quando necessário, as mães são encaminhadas para outros serviços ou profissionais.

Pela escassez de recursos humanos de enfermagem, estas reuniões foram suspensas por alguns meses mas, atualmente, o grupo de apoio aos pais é coordenado pela enfermeira da UCIN, uma vez por semana, havendo também a participação da enfermeira do berçário de prematuros e do banco de leite. Nas primeiras reuniões os pais recebem material didático 
instrucional contendo fotos e explicações, em terminologia simplificada, sobre as alterações clínicas e equipamentos freqüentemente utilizados na assistência a esses recém-nascidos em cuidado intensivo (Ferlin et al., 1995).

Numa avaliação preliminar dessa experiência com o grupo de pais percebemos uma maior articulação das ações de enfermagem da UCIN, do berçário de prematuros e do banco de leite, incentivando o aleitamento materno, bem como uma maior satisfação dos pais pela assistência recebida, possibilitando a troca de experiência entre pais que vivenciaram situações semelhantes, a auto-ajuda, o esclarecimento de dúvidas acerca do processo terapêutico do filho e do auto-cuidado, entre outras. $\mathrm{O}$ apoio recebido das enfermeiras e dos participantes das reuniöes tem auxiliado as mães/pais no enfrentamento da crise vivenciada pelo nascimento de um filho prematuro e de alto risco que requer assistência em terapia intensiva.

Uma visita domiciliar é solicitada à enfermagem de saúde pública da própria instituição, sendo realizada por ocasião da alta materna para orientações e acompanhamento da puérpera, estimulando-se o aleitamento matemo, bem como levantam-se as condiçőes sócio-econômicas.

Outros indicadores do impacto positivo desses grupos de apoio são a grande participação e freqüência das mães/pais nas reuniões, na UCIN e no berçário de prematuros, a melhoria da interação com o bebê e do relacionamento com a equipe de enfermagem.

Todavia, ressaltamos que a simples implantação dessas reuniőes com os pais não assegura $o$ alcance dos objetivos almejados se os profissionais não tiverem sensibilidade $e$ conhecimento suficientes para lidarem com as emoçōes e sentimentos expressos pela clientela, assim como a retaguarda de outros serviços de apoio multiprofissional.

Após estabilizar a condição clínica, a criança é transferida para o berçário de prematuros, no qual a mãe envolve-se mais com os cuidados direto do filho, recebendo da enfermagem orientações especificas como parte do preparo para a alta hospitalar. Esse treinamento é individualizado e feito pela enfermeira, que utiliza-se de técnicas de demonstração, e de videos sobre aleitamento materno, banho e massagem do bebê. Estimula-se as mães a trazerem brinquedos próprios para ficarem no berço ou incubadora, bem como vestimentas pessoais, com vistas a personalizar o atendimento e a unidade da criança. Após a alta, muitas dessas mães retornam para visitar os profissionais do berçário trazendo fotografia do filho, a qual é colocada em mural localizado na UCIN e no berçário de prematuros (Silva et al., 1996).

Uma outra experiência de atendimento aos pais é a de um hospital-escola de CuiabáMT, em que apesar da preocupação da equipe da unidade neonatal, os pais/familia da criança prematura ainda estão muito afastados do filho durante a internação. Assim como na maioria dos serviços, esse também não possui alojamento conjunto tardio. Os pais têm as visitas liberadas e podem ficar com o filho durante o periodo diurno e prestar cuidados desde que estejam preparados para tal. A mãe é estimulada a cuidar do filho assim que esse tem sua condição clínica estabilizada. A enfermeira/equipe de enfermagem é a responsável por prestar as orientaçőes gerais para a família, e à equipe médica cabe dar as informações acerca do estado clínico do bebê. Como não existe grupo de apoio aos pais no serviço, as orientaçöes e apoio são oferecidas de acordo com as necessidades detectadas pela equipe no decorrer da internação. Por ocasião da alta, os pais recebem informações de como cuidar do filho no domicílio e da importância do seguimento ambulatorial.

Tanto as pesquisas como os eventos científicos na área de pediatria muito têm discutido a questão da humanização da assistência ao bebê prematuro e a incorporação dos pais nos cuidados. No entanto, o que se percebe é que as dificuldades estão em adequar as propostas às realidades específicas de cada serviço.

\section{CONSIDERAÇÕES FINAIS}

Compreendemos que a enfermagem exerce um papel fundamental nas unidades de 
internação neonatal a fim de proporcionar uma assistência humanizada aos pais de crianças prematuras e de baixo peso ao nascer. A equipe de enfermagem ao manter um contato permanente com os pais, tem possibilidades de implementar medidas que visem maior interação pais-bebê e com os profissionais de saúde.

O que se percebe é que a familia do prematuro ainda não é preocupação básica de toda a equipe de saúde. A assistência a essas crianças ainda tem ênfase no aspecto clínico e de cuidados técnicos, deixando em segundo plano o envolvimento com a família. Percebemos também, que em virtude da priorização dos cuidados clínicos ao prematuro, apesar de existir, na maioria dos serviços, algumas atividades com os pais, em especial por ocasião da alta hospitalar, os enfermeiros acabam se envolvendo mais com a assistência direta e com a burocracia da unidade e as atividades de apoio à família são sempre deixadas de lado, senão realizadas informalmente de maneira assistemática.

Destacamos algumas intervenções que podem favorecer a adaptação dos pais a nova situação e o fortalecimento do vínculo entre pais-bebê, como: o livre acesso dos pais ao berçário; incentivo ao contato físico precoce; implantação de grupos de apoio envolvendo equipe multiprofissional e pais de bebês em diferentes estágios de evolução clínica; incentivo ao aleitamento materno e à execução de cuidados diretos ao filho; estruturação de redes de apoio formal e informal dirigidas aos pais e familiares durante a hospitalização do filho e após a alta hospitalar.

Ressaltamos que estas medidas são parte integrante da assistência aos pais/família, no entanto, as relações que se estabelecem entre a família e os profissionais de saúde são complexas, envolvendo aspectos biológicos, sociais e subjetivos.

Há necessidade de se ampliar a participação dos pais/familia nas unidades neonatais, inclusive durante o cuidado intensivo, contemplando o contexto social e familiar de cada criança, permitindo uma assistência mais integral e humanizada.

A inserção dos pais e famílias desses bebês de risco como parte integrante da assistência neonatal é um processo em construção, no qual se deve buscar alternativas para conciliar o atendimento das necessidades biológicas do prematuro com aquelas psico-sociais desse ser em crescimento e desenvolvimento, que por sua vez é parte de uma família que também necessita de cuidados face aos eventos que está vivenciando.

Para tanto, torna-se imprescindivel instrumentalizar a equipe de saúde que assiste essa clientela com estratégias e conhecimentos técnicos-científicos para dar conta das novas necessidades que se apresentam neste processo de trabalho em construção, na perspectiva de superar a dicotomia preventivo/curativo e individual/coletivo do modelo de atenção a saúde vigente.

ABSTRACT: The purpose of this study is to reflect about the assistance to be given to parents of preterm and low weight babies, born in neonatal units, based on existing literature and the authors' practical experiences. Although mothers right to be close to their babies is assured by law, most of the nurseries still keep strict visit schedules to parents. However, there are some units where mothers' permanency is allowed. The question, in these cases, is if parents effective involvement in the care of the baby should or should not be allowed. For the nursing care unit, the authors suggest some intervention strategies to adapt parents to the new situation, and to strengthen the relationship between them and the baby. The recommendations are as follows: parents free access to the nurseries; motivation of early physical contact between parents and baby; implementation of multi-professional support groups to help parents during the different stages of clinical evolution; incentive for breastfeeding, and direct care of the babies; structuring of formal and informal groups of support for parents during and after hospitalization.

KEYWORDS: nursing care, parents, pre-term newborn 
RESUMEN: El objetivo de este trabajo es hacer una reflexión sobre la asistencia a los padres de niños prematuros cuyo peso fue bajo al nacer. Dicha atención a los padres se da en las unidades neonatales, con base en datos de la literatura y en experiencias prácticas de las autoras. Aunque el derecho materno de permanecer junto al hijo esté asegurado por ley, la gran mayoria de las unidades de cuidados neonatales tienen unos horarios de visita bastante restrictos. Sin embargo, otros servicios liberan totalmente la permanencia de la madre en estas unidades, y además, existe la duda y se discute si seria conveniente tal envolvimiento efectivo de los padres respecto a los cuidados con el hijo. En la asistencia de enfermeria, las autoras sugieren estrategias de intervención que visen la adaptación de los padres a la nueva situación y al fortalecimiento del vínculo entre los padres y el bebé. Entre ellas destacamos: el libre acceso de los padres a la unidad; incentivo al contacto fisico precoz entre padres e hijo; implementación de grupos de apoyo involucrando el equipo multiprofesional y padres de bebés en diferentes etapas de evolución clinica; incentivo a la lactancia materna y a que practiquen cuidados directamente al hijo; desarrollo de redes de apoyo formal e informal dirigidas a los padres durante la hospitalización del hijo y después de la salida del hospital.

PALABRAS CLAVE: asistencia de enfermeria, padres, recién nacidos, prematuros

\section{REFERÊNCIAS BIBLIOGRÁFICAS}

ALBERMAN, E.; EVANS, S. J.W. A epidemiologia da prematuridade: etiologia, freqũência e prognóstico. Anais Nestlé, v. 44, p. 5-24, 1992.

AVERY, G. B. The morality of drastic intervention. In: AVERY, G. B.; FLETCHER, M. A. ; MacDONALD, M. G. Neonatology: pathophysiology and management of newborn. 4. ed. Philadelphia: J. B. Lippincott, 1994 , p. .8-11.

BADINTER, E. Um amor conquistado: o mito do amor materno. 8 ed. Rio de Janeiro: Nova Fronteira, 1985.

BERTHOUD, C. M. E. Formando e rompendo vinculos: a grande aventura da vida. In: BERTHOUD, C M. E.; BROMBERG, M. H. P. F.; BORREGO, M. R. M. C. Ensaios sobre a formação e rompimentos de vínculos afetivos. Săo Paulo: Cabral, 1997. Cap. 1, p. 13-42.

BOWLBY, J, Cuidados maternos e saúde mental. São Paulo: Martins Fontes, 1995.

BRASIL. Ministério da Saúde. Ministério da Criança / Projeto Minha Gente. Estatuto da criança e do adolescente. Brasilia, 1991, 110p.

BRAZELTON, B. T. O desenvolvimento do apego: uma familia em formação. Porto Alegre: Artes Médicas, 1988.

FERLIN, M. L. S. et al. O recém-nascido na unidade de terapia intensiva neonatal. Hospital das Clinicas da Faculdade de Medicina de Ribeirão Preto - USP, 37 p., 1995.

FERRAZ, M. A.; CHAVES, R. L. Bebês prematuros: aspectos emocionais envolvidos. Pediatria Moderna, v. 32, n. 7, p. $784-790,1996$

GENNARO, S. Family response to the low birth weight infant. Nursing Clinics of North America, v. 31 , ก. 2 , jun. 1996 . 
JAVORSKI, M. Os significados do aleitamento materno para mäes de prematuros em cuidado canguru. Ribeirão Preto, 1997. 177p. Dissertação (Mestrado). Escola de Enfermagem de Ribeirão Preto, Universidade de São Paulo.

KLAUS, M. H.; KENNELL, H. J. Assistência aos pais In: KLAUS, M. H.; FANAROFF, A. A. O alto risco em neonatologia. 2. ed. Rio de Janeiro: Interamericana, 1982. p. 141-165.

Pais e bebês: a formação do apego. Porto Alegre: Artes Médicas, 1993.

Assistência aos pais. In: KLAUS, M. H.; FANAROFF, A. A. Alto risco em neonatologia. 4. ed. Rio de Janeiro: Guanabara Koogan, 1995. p. 139-155.

LAMY, Z. C. Estudo das situaçōes vivenciadas por pais de recém-nascidos internados em unidade de terapia intensiva neonatal. Rio de Janeiro, 1995. 200p. Dissertação (Mestrado), Fundação Oswaldo Cruz.

MCLOUGHLIN, A.M. Formal and informal support for mothers who have had a baby in neonatal Intensive Care Unit. Manchester, U. K., 1995. 449p. Tese (Doutorado). University of Manchester.

OEHLER, J. M. Developmental care of low birth weight infants. Advances in Clinical Nursing Research, v. 28 , n. 2, p. $289-297,1993$.

SILVA, M. H. A et al. Assistência aos pais de crianças de alto risco em unidade de terapia intensiva neonatal: experiência do Hospital das Clinicas de Ribeirão Preto. In: CONGRESSO BRASILEIRO DE PERINATOLOGIA, 15., 1996, Belo Horizonte - MG, 1996. Anais... Belo Horizonte: Sociedade Brasileira de Perinatologia, 1996. p. 96.

SLUCKIN, M.; HERBERT, M.; SLUCKIN, A. Vinculo materno. São Paulo: Ediçōes Paulinas, 1990.

STEELE, K. Caring for parents of critically ill neonates during hospitalization strategies for health care professionals. Maternal-Child Nursing Journal, v. 16, n. 1, p. 13-27, 1987.

STJERNVIST, K. M. Extremely low birth weight infant less than $901 \mathrm{~g}$. Impact on the family during the first year. Scan. J. Soc. Med., v. 4, n. 226-33, 1992.

VIGGIANO, M. G. C.; XIMENES, Y. R. Prematuridade (aspectos obstétricos). In: FONTES, J. A S Perinatologia Social. São Paulo: Fundo Editorial BYK, 1984. Cap. 25, p. 256-272.

WAHERS, N. E.; KRISTIANSEN, C. M. Two evoluations of combined mother-infant versus separate post natal nursing care. Res. Nurs. Health, v. 18, n.1 p. 17-26, 1995.

ZAHR, L. K et al. Follow-up of premature infants of low socioeconomic status. Nursing Research, v. 38, n. 4, 1989. 